\title{
PENENTUAN KANDUNGAN PIGMEN KAROTENOID PADA KEPITING Grapsus albolineatus (Lamarck) BETINA DARI PERAIRAN PESISIR PANTAI DESA TANAWANGKO
}

\author{
(Determination of Pigment Carotenoid in Crafts of Grapsus albolineatus (Lamarck) \\ Female from the Coastal Waters of Tanawangko Village Beach)
}

\section{Sutandi Makalalag ${ }^{1 *}$, Darus Saadah J. Paransa ${ }^{1}$, Desy M H. Mantiri ${ }^{1}$}

1. Program studi IImu Kelautan, Fakultas Perikanan dan IImu Kelautan, Universitas Sam Ratulangi, Manado.

*e-mail : tandi.makalalag@yahoo.com

Grapsus albolineatus (Lamarck) is one of the species of blackish-green crab found above or below the coastal rocks. At has long legs and no swimming legs and has a small claw. Purple capitals, is characteristic of this type of crab., the G. albolineatus crab has an attractive color on the carapace organ that indicates the presence of pigment content. This study was aimed to determined the content and it's pigment type of the organs of the carapace, epidermal layer, hepatopancreas, blood and gonads in the female G. albolineatus (Lamarck) crab. The method of this research in order to separated and determinated of pigment content by using thin layer chromatography (TLC) method. The results obtained in this study were the total pigment content of $G$. albolineatus crab showed the highest value in gonad organ with value $34,41 \mu \mathrm{g}$, followed by epidermal layer organ $12,19 \mu \mathrm{g}$, hepatopancreas $9,61 \mu \mathrm{g}$, blood $1,06 \mu \mathrm{g}$ and carapace $0.42 \mu \mathrm{g}$. the pigment content of the gonads organ has the highest value compared with other organs, it is presumed that the female $G$. albolineatus crab is at the mature stage of the gonad, so that the carotenoid pigment is still accumulated on the gonad organ used for the gonadal maturation process. The types of pigment identified in the extract of the carapace organ, epidermal layer, hepatopancreas, gonads and blood from female $G$. albolineatus crabs with semipolar solution of Petroleum Eter and Acetone are: $\beta$-carotene, echinone, kantaksantin, adonirubin type, astaxanthine and astacene .

Keywords: Grapsus albolineatus, TLC, pigment

Grapsus albolineatus (Lamarck) merupakan salah satu spesies kepiting yang berwarna hitam kehijauan yang ditemukan di atas atau di bawah batu pantai. Memiliki kaki jalan yang panjang dan tidak memiliki kaki renang serta memiliki capit yang berukuran kecil. Capit berwarna ungu, merupakan ciri khas kepiting jenis ini. Kepiting G. albolineatus memiliki warna yang menarik pada organ karapas yang mengindikasikan adanya kandungan pigmen. Penelitian ini bertujuan untuk menentukan kandungan dan jenis pigmen pada organ karapas, lapisan epidermis, hepatopankreas, darah dan gonad pada kepiting G. albolineatus (Lamarck) betina. Pemisahan yang umum digunakan dalam penentuan jenis pigmen karotenoid adalah menggunakan metode Kromatografi Lapis Tipis. Pemisahan ini dikenal karena proses pemisahannya mudah, sederhana dan membutuhkan waktu yang relatif singkat serta dapat menghasilkan data yang akurat. Hasil yang diperoleh dalam penelitian ini adalah kandungan pigmen total dari kepiting $G$. albolineatus menunjukkan nilai tertinggi pada organ gonad dengan nilai $34,41 \mu \mathrm{g}$, diikuti organ lapisan epidermis $12,19 \mu \mathrm{g}$, hepatopankreas $9,61 \mu \mathrm{g}$, darah 1,06 $\mu \mathrm{g}$ dan karapas $0,42 \mu \mathrm{g}$. kandungan pigmen pada organ gonad memiliki nilai tertinggi dibandingkan dengan organ lainnya, diduga kepiting $G$. albolineatus betina ini berada pada tahap matang gonad, sehingga pigmen karotenoid masih tertumpuk pada organ gonad yang digunakan untuk proses pematangan gonad. Jenis-jenis pigmen yang teridentifikasi pada ekstrak organ karapas, lapisan epidermis, hepatopankreas, gonad dan darah dari kepiting $G$. albolineatus betina dengan larutan pengembang PE dan Aseton (80:20) yang bersifat semipolar yaitu: $\beta$-karoten, ekinenon, kantaksantin, tipe adonirubin, astaksantin dan astasen.

Kata kunci : Grapsus albolineatus, KLT, pigmen 


\section{PENDAHULUAN}

Salah satu organisme laut yang menjadi kekayaan Sulawesi Utara diantaranya adalah kepiting (Nontji 1993). Menurut Poore (2004) kepiting merupakan salah satu organisme laut yang termasuk dalam golongan krustasea. Bliss and Mantel (1982) mengatakan beberapa diantaranya memiliki nilai ekonomis tinggi untuk dikonsumsi seperti Scylla serrata. Selanjutnya Susetiono, (2004) mengemukakan di alam juga ditemukan jenis kepiting yang tidak dapat dikonsumsi seperti Grapsus sp (Lamarck). Grapsus albolineatus (Lamarck) spesies berwarna hitam kehijauan yang ditemukan di atas atau di bawah batu pantai (Majchacheep, 1989). Kepiting G. albolineatus memiliki warna yang menarik pada organ karapas yang mengindikasikan adanya kandungan pigmen (Susetiono 2004; Majchacheep, 1989). Mantiri (2004) mengemukakan hasil penelitiannya, bahwa pada lobster Eropa terdapat zat warna yang dikenal dengan nama pigmen astaksantin yang merupakan pigmen karotenoid.

Menurut Britton et al. (2008) pigmen karatenoid merupakan prekursor vitamin A yang berguna bagi tubuh manusia yang dimetabolisme dari $\beta$-karoten. Didalam tubuh manusia precursor vitamin A akan dimetabolisme menjadi vitamin A yang sangat berguna bagi aktivitas fisiologi terutama organ mata, melindungi jaringan permukaan kulit dari sinar matahari yang tinggi, antioksidan dan antikanker (Landrum, 2010).

Pemisahan yang umum digunakan dalam menentukan jenis pigmen karotenoid adalah menggunakan metode Kromatografi Lapis Tipis $(\mathrm{KLT})$. Pemisahan ini dikenal karena proses pemisahannya yang mudah, sederhana dan membutuhkan waktu yang relatif singkat serta menghasilkan data yang akurat (Ismunandar, 2006; Chang, 2010). Menurut Stahl (1985); Chang (2010) bahwa analisis Kromatografi Lapis Tipis (KLT) mempunyai keunggulan sebagai suatu teknik kromatografi yang dapat menganalisis berbagai senyawa dan campuran senyawa secara serempak berdasarkan beda polaritas.

Mantiri (1997) mengemukakan bahwa tahap pengembangan menggunakan metode KLT untuk menentukan polaritas jenis pigmen pada krustasea dengan larutan pengembang yang paling baik adalah pengembang semipolar yaitu Pertroleum Eter (PE) dan Aseton. Hal yang sama juga dilakukan oleh Thamin et al. (2006), untuk memisahan pigmen dari suatu organisme dilakukan dengan memanfaatkan larutan pengembang semipolar. Pemisahan pigmen karotenoid pada krustasea dilakukan dengan memanfaatkan larutan Petroleum eter (PE). Pada penelitian ini tujuan yang hendak dicapai yaitu menentukan kandungan pigmen pada organ karapas, lapisan epidermis, hepatopankreas, darah dan gonad kepiting $G$. albolineatus (Lamarck) betina dan menentukan jenis pigmen pada organ karapas, lapisan epidermis, hepatopankreas, darah dan gonad kepiting G. albolineatus betina melalui pemisahan Kromatografi Lapis Tipis.

\section{METODE PENELITIAN}

Sampel kepiting $G$. albolineatus betina diambil dari perairan pesisir pantai desa Tanawangko Kec. Tombariri, Kabupaten Minahasa. Sampel yang diperoleh selanjutnya 
dibawa ke Laboratorium Teknologi Akuakultur Fakultas Perikanan dan IImu Kelautan UNSRAT untuk diadakan tahapan penelitian selanjutnya. Analisis kandungan pigmen dengan menggunakan spektrofotometer.

Pengambilan sampel dilakukan pada saat air surut dengan cara menangkap langsung dengan tangan. Identifikasi dilakukan melalui pengamatan morfologi kepiting dituntun dengan buku identifikasi Majchacheep 1989. Sampel kemudian dibedah untuk memisahkan organ dalam dari organ luarnya dengan menggunakan alat bantu pisau dan pinset. Organ dalam maupun organ luar tersebut kemudian ditimbang sebelum dilakukan proses ekstraksi. Sebelum diekstrak karapas terlebih dahulu direndam dengan larutan $\mathrm{HCL} 0,5 \mathrm{~N}$.

Masing-masing organ yang digunakan digerus dengan alat penggerus dan dicampur dengan aseton kemudian disaring dengan menggunakan kertas saring. Hasil ekstraknya dimasukkan ke dalam labu pemisah dan ditambahkan dengan PE. Supernatan pigmen dalam larutan PE kemudian dianalisis menggunakan alat spektrofotometer UV VIS. Pembacaan absorbansi dilakukan pada panjang gelombang 380-550 nm, sehingga akan diperoleh kurva dengan sumbu $X$ sebagai panjang gelombang dan sumbu $Y$ sebagai absorban serta akan diperlihatkan serapan maksimum pada panjang gelombang tertentu (Britton et al., 2004).Sisa atau residu organ tubuh yang telah diambil ekstrak pigmennya dikeringkan dalam oven dengan suhu $60{ }^{\circ} \mathrm{C}$ selama 24 jam, kemudian ditimbang untuk mengetahui berat residu kering.

Kandungan pigmen dan konsentrasi pigmen dalam tubuh organisme dapat diketahui dengan menggunakan formula matematis (Britton, et al. 1995).

Untuk penentuan jenis pigmen pada ekstrak karatenoid menggunakan pemisahan dengan KLT dengan mengikuti metode Matsjeh (1999) yang meliputi penyiapan pelat, aplikasi sampel, pengembangan pelat dan visualisasi.

\section{HASIL DAN PEMBAHASAN}

Sampel kepiting $G$. albolineatus (Lamarck) betina yang digunakan dalam penelitian ini memiliki berat segar $17,38 \mathrm{~g}$, panjang karapas $3,8 \mathrm{~cm}$ dengan warna tubuh hijau kehitaman (Gambar 2). Kepiting G. albolineatus diperoleh dari sekitar perairan pesisir pantai Desa Tanawangko.

Hasil ekstraksi pigmen total karotenoid dalam larutan Petroleum Eter (PE) pada organ gonad, darah, hepatopankreas, lapisan epidermis dan karapas dari kepiting $G$. albolineatus betina dianalisis dengan menggunakan spektrofotometer UV VIS yang menghasilkan data seperti pada Tabel 1.

Tabel 1. Serapan maksimum spektrofotometer pada ekstrak pigmen total dengan pengembang PE dan Aseton (80:20).

\begin{tabular}{cc}
\hline Organ Tubuh & Panjang Gelombang $(\mathrm{nm})$ \\
\hline Karapas & 474 \\
Lapisan epidermis & $394,424,450$ \\
Hepatopankreas & $424,449,475$ \\
Darah & 448,474 \\
Gonad & $423,449,474$ \\
\hline
\end{tabular}




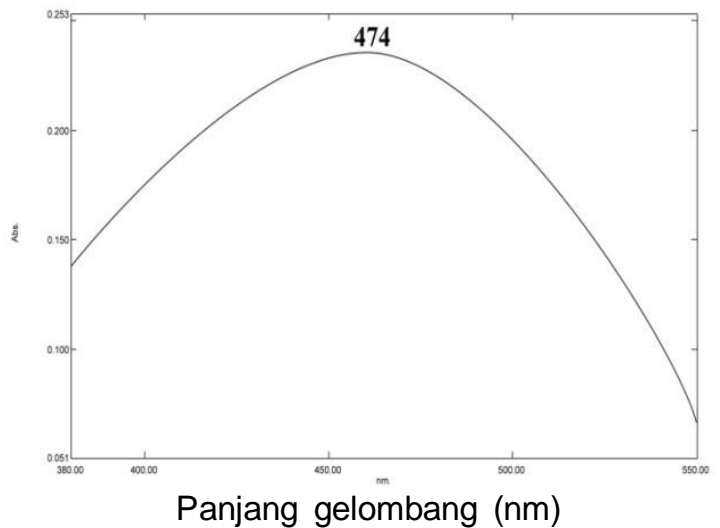

Gambar 1. Spektrogram ekstrak pigmen total organ karapas kepiting $G$. albolineatus.

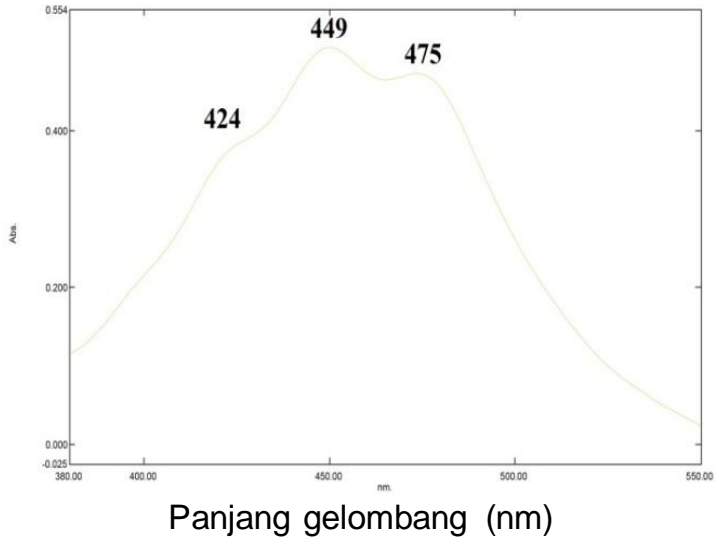

Gambar 3. Spektrogram ekstrak pigmen total organ hepatopankreas kepiting $G$. albolineatus.

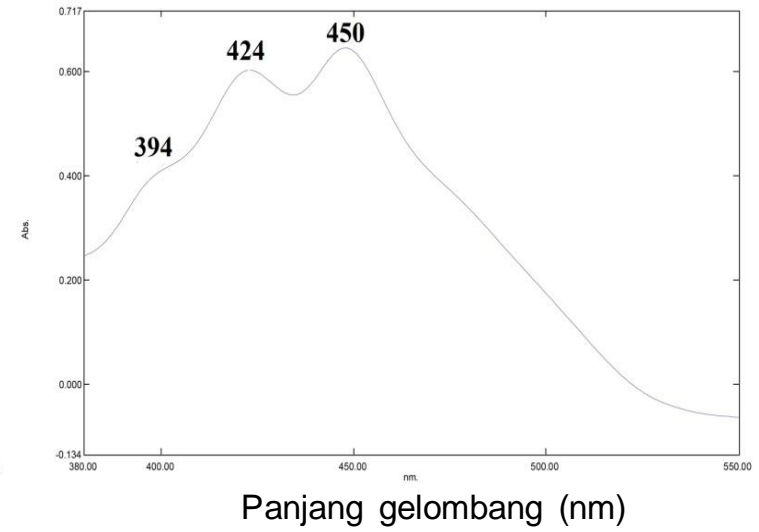

Gambar 2. Spektrogram ekstrak pigmen total organ lapisan epidermis kepiting $G$. albolineatus.

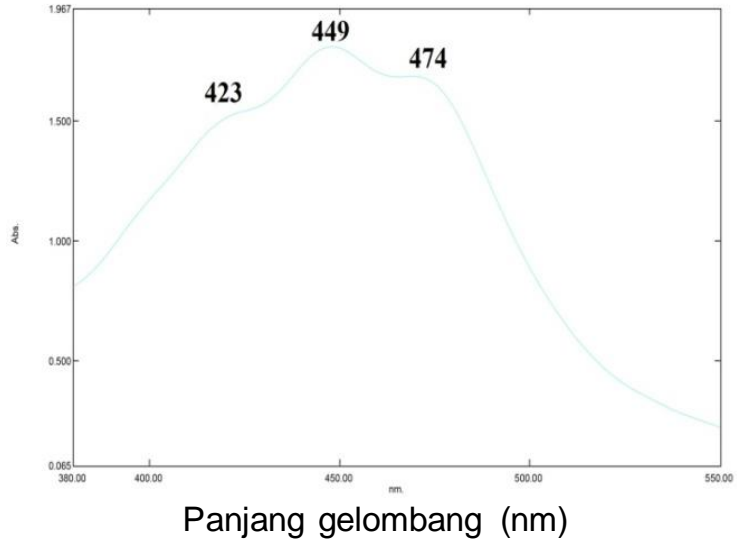

Gambar 4. Spektrogram ekstrak pigmen total organ gonad kepiting $G$. albolineatus.

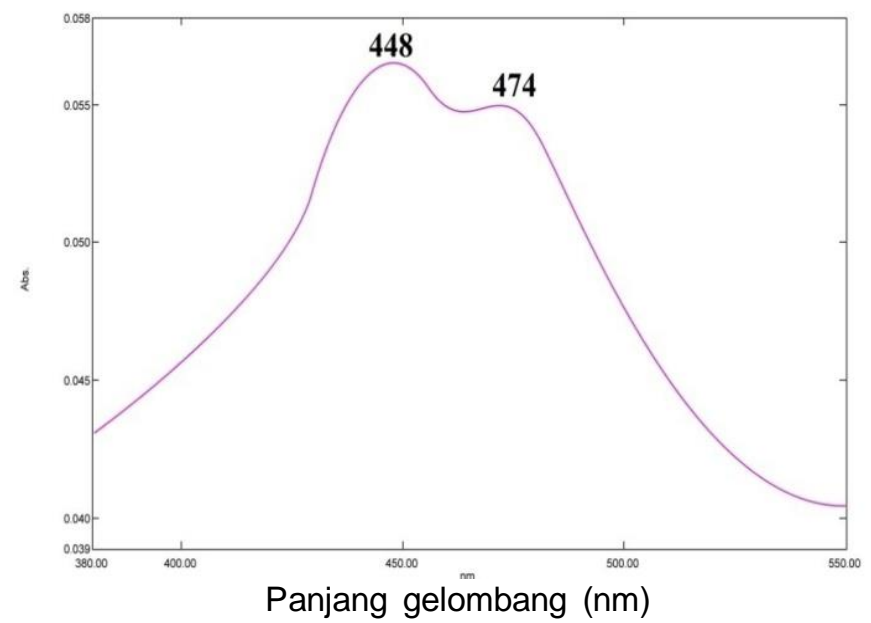

Gambar 5. Spektrogram ekstrak pigmen total organ darah kepiting G. albolineatus. 
Pada ekstrak organ karapas membentuk serapan maksimum pada panjang gelombang $474 \mathrm{~nm}$. Bentuk spektrogram yang dihasilkan seperti yang tampak pada spektrogram gambar 1. Spektrogram ekstrak organ karapas membentuk satu puncak gelombang. Bentuk spektrogram dari ekstrak pigmen total organ karapas di atas menurut Britton et al.. (2004) tidak dapat menentukan jenis pigmen karena bentuk puncak yang dihasilkan masih melebar. Menurut Packer (1992) bahwa pada ekstrak pigmen total masih mengandung pencampuran senyawa pigmen karotenoid.

Ekstrak pigmen total organ lapisan epidermis melalui serapan spektrofotometer UV VIS membentuk serapan maksimum spektrofotometer pada panjang gelombang 394, 424 dan $450 \mathrm{~nm}$ dengan tiga puncak gelombang maksimum. Bentuk spektrogram di bawah dari hasil serapan maksimum spektrofotometer membentuk 2 puncak gelombang dan satu lekukan seperti yang tampak pada Gambar 2

Pada ekstrak pigmen total organ hepatopankreas kepiting $G$. albolineatus betina membentuk serapan maksimum pada panjang gelombang 424, 449 dan 475 nm. Hasil analisis spektrogram pada organ hepatopankreas terbentuk 2 puncak gelombang dan satu lekukan seperti yang tampak pada gambar 3 di atas

Ekstrak pigmen total dari organ gonad kepiting $G$. albolineatus betina dianalisis dengan menggunakan alat spektrofotometer UV VIS.
Serapan spektrofotometer UV VIS membentuk puncak gelombang (Gambar 4) di atas. Berdasarkan hasil spektrogram terbentuk tiga puncak serapan maksimum yang berada pada panjang gelombang 423, 449 dan 474 $\mathrm{nm}$. Bentuk spektrogram dari hasil ekstraksi pigmen total organ gonad membentuk tiga puncak gelombang maksimum.

Bentuk spektrogram dari ekstrak pigmen total organ karapas, lapisan epidermis, hepatopankreas, gonad, dan darah diasumsikan masih terjadi pencampuran senyawa pigmen dalam ekstrak. Menurut Britton et al. (2004) pencampuran pigmen tersebut karena dalam ekstrak pigmen total masih terdapat beberapa jenis pigmen karotenoid yang masih saling mengikat antara pigmen karoten dengan pigmen xantofil atau satu jenis pigmen dengan asam lemak.

Berdasarkan hasil perhitungan konsentrasi pigmen karotenoid pada organ kepiting $G$. albolineatus betina diperoleh nilai tertinggi berada pada organ gonad dan darah dengan nilai $3441,90 \mu \mathrm{g} / \mathrm{g}$ berat residu kering, diikuti organ lapisan epidermis, hepatopankreas dan karapas. Sedangkan nilai kandungan pigmen total dari kepiting $G$. albolineatus menunjukkan nilai tertinggi pada organ gonad dengan nilai 34,41 $\mu \mathrm{g}$, diikuti organ lapisan epidermis, hepatopankreas, darah dan karapas.

Tabel 2. Kandungan dan Konsentrasi Pigmen Karotenoid Pada Kepiting G. albolineatus betina.

\begin{tabular}{ccc}
\hline & $\begin{array}{c}\text { Konsentrasi Pigmen( C ) } \\
\text { Organ tubuh }\end{array}$ & $\begin{array}{c}\text { Kandungan Pigmen }(\mathrm{Q}) \\
(\mu \mathrm{g})\end{array}$ \\
\hline Karapas & 4,26 & 0,42 \\
Lapisan epidermis & 1219,04 & 12,19 \\
Hepatopankreas & 961,90 & 9,61 \\
Gonad & 3441,90 & 34,41 \\
Darah & 3441,90 & 1,06 \\
\hline
\end{tabular}


Konsentrasi dan kandungan pigmen pada organ gonad memiliki nilai tertinggi dibandingkan dengan organ lainnya, diduga kepiting G.albolineatus betina ini berada pada tahap matang gonad, sehingga pigmen karotenoid masih tertumpuk pada organ gonad yang digunakan untuk proses pematangan gonad Menurut Ruppert and Barnes (1994) bahwa krustasea yang sedang dalam tahap fisiologi matang gonad membutuhkan banyak energi untuk proses pematangan gonad.

Pigmen total dari ekstrak kepiting $G$. albolineatus betina dipisahkan menggunakan metode analisis Kromatografi Lapis Tipis (KLT). Pemisahan ini bertujuan untuk menentukan jenis-jenis pigmen yang terkandung di dalam ekstrak organ karapas, lapisan epidermis, hepatopankreas, gonad dan darah dari kepiting $G$. albolineatus betina. Hasil pengembangan dengan menggunakan larutan PE dan Aseton menunjukkan migrasi pigmen dari organ karapas, lapisan epidermis, hepatopankreas, darah dan gonad di atas plat silika gel menghasilkan terbentuknya 8 pemisahan fraksi pigmen seperti yang tampak pada Gambar 6.

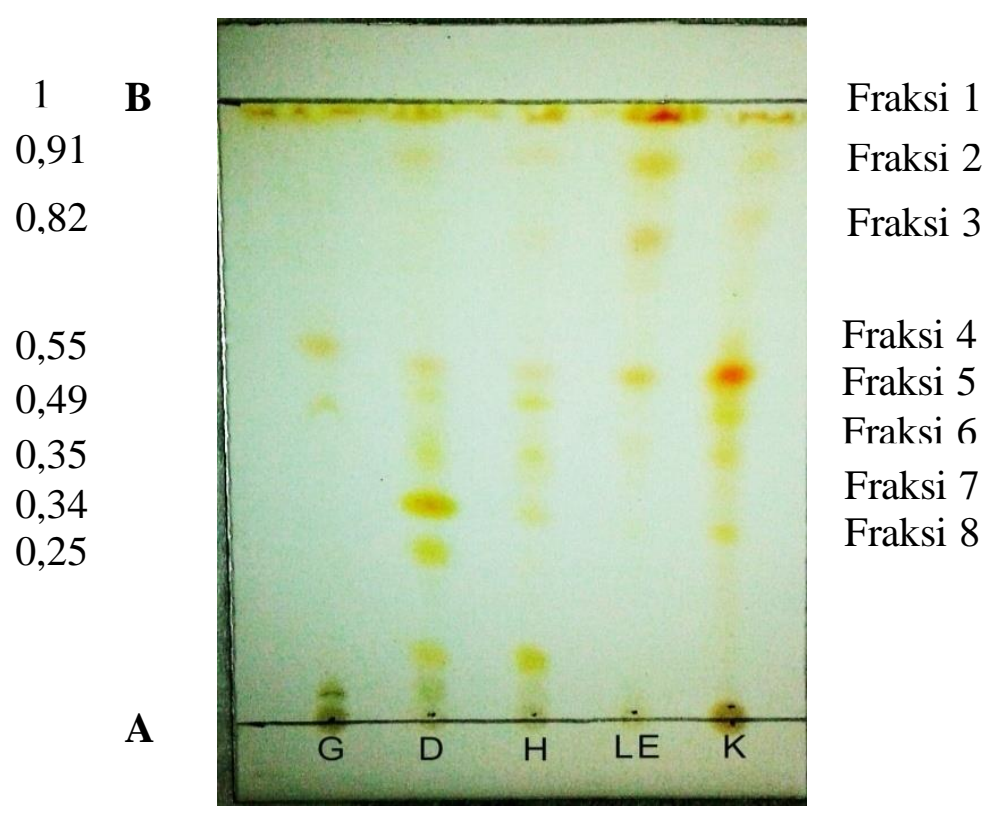

Ket: $\begin{array}{cc}\text { A } & : \text { Titik Awal } \\ \text { B } & : \text { Titik Akhir }\end{array}$

Gambar 6. Kromatogram hasil migrasi ekstrak pigmen total dengan pengembang PE dan Aseton (80:20). 
Tabel 3. Hasil analisis KLT dan serapan spektrofotometer dengan larutan pengembang PE dan Aseton (80:20) dari ekstrak pigmen total.

\begin{tabular}{ccccc}
\hline FRAKSI & RF & WARNA & $\begin{array}{c}\text { PANJANG } \\
\text { GELOMBANG }\end{array}$ & JENIS PIGMEN \\
\hline 1 & 1.00 & Kuning & $425,450,485$ & $\beta$-Karoten \\
2 & 0.91 & Kuning & 459 & Ekinenon \\
3 & 0.82 & Kemerahan & 468 & Kantaksantin \\
4 & 0.55 & Kuning & 454,472 & Tipe Adonirubin \\
5 & 0.49 & Kemerahan & 477 & Astaksantin \\
6 & 0.35 & Kuning & - & Tidak teridentifikasi \\
7 & 0.34 & Kemerahan & 473 & Astasen \\
8 & 0.25 & Kuning & - & Tidak teridentifikasi \\
\hline
\end{tabular}

Hasil isolasi pigmen pada fraksi 1 memiliki nilai Rf 1,00 serta menghasilkan warna kuning yang nampak di atas plat silika gel. Pada fraksi 1 ini dengan pengembang PE dan Aseton (80:20) yang bersifat semipolar membentuk tiga puncak serapan maksimum spektrofotometer yaitu 425, 450 dan $485 . \quad$ Menurut Britton et al.. (1995) bahwa ketiga puncak serapan maksimum tersebut teridentifikasi sebagai pigmen $\beta$ karoten. Hasil penelitian Paransa et al. (2002) pada kepiting G. albolineatus betina yang ditangkap dari pantai Kalasey, ditemukan jenis pigmen $\beta$ karoten pada $\operatorname{Rf} 1$. Pigmen $\beta$-karoten ditemukan baik dari hasil elusi kedua pengembang PE dan Aseton (80:20) dan (95:5).

Fraksi 2 dengan nilai $\mathrm{Rf}$ 0,91, pada plat silika gel menghasilkan warna kuning. Hasil serapan maksimum spektrofotometer pada fraksi 2 memliki satu puncak pada panjang gelombang $459 \mathrm{~nm}$. Menurut Britton et al. (1995) bahwa serapan maksimum spektrofotometer yang terdapat pada panjang gelombang $459 \mathrm{~nm}$ teridentifikasi sebagai pigmen ekinenon. Hasil penelitian Paransa et al. (2002) kepiting $G$. albolineatus betina yang ditangkap dari pantai di daerah perbatasan Kalasey-Manado juga ditemukan pigmen tipe ekinenon yang terdapat pada fraksi 2 .

Hasil isolasi pada fraksi 3 memiliki nilai $\mathrm{Rf} 0,82$ dan menghasilkan warna kemerahan pada plat silika gel. Serapan maksimum spektrofotometer membentuk kurva spektrogram dengan panjang gelombang $468 \mathrm{~nm}$. Menurut Britton et al. (1995); Britton et al. (2004) bahwa serapan maksimum spektrofotometer yang terdapat pada panjang gelombang $468 \mathrm{~nm}$ teridentifikasi sebagai pigmen kantaksantin. Selanjutnya hasil penelitian Paransa dan Abdullah (2007) melaporkan pada kepiting Scylla serrata jantan yang ditangkap dari perairan bakau Ratatotok ditemukan juga pigmen tipe kantaksantin pada organ lapisan epidermis.

Fraksi 4 pada hasil KLT menurut gambar 2 memiliki nilai Rf 0,55 dan menghasilkan warna kuning pada plat silika gel. Serapan maksimum spektrofotometer membentuk dua puncak pada panjang gelombang 454, $472 \mathrm{~nm}$. Menurut Britton et al. (1995) serapan maksimum spektrofotometer dari fraksi 4 teridentifikasi jenis pigmen tipe adonirubin.

Hasil pemisahan menggunakan KLT Pada fraksi 5 memiliki nilai Rf 0,49 dan nampak pada plat silika dengan warna kemerahan. Hasil serapan 
maksimum spektrofotometer berada pada panjang gelombangs $477 \mathrm{~nm}$. Menurut Britton et al. (1995) bahwa serapan maksimum panjang gelombang pada $477 \mathrm{~nm}$ teridentifikasi sebagai pigmen astaksantin. Hasil penelitian Mantiri et al. (2002), Uca vocans jantan ditangkap di tiga lokasi yakni perairan Molas, Kauditan dan Likupang terdapat pigmen astaksantin bebas yang terdistribusi pada semua organ tubuh.

Hasil isolasi pada Fraksi 6 memiliki nilai $\operatorname{Rf} 0,35$ dan menampilkan warna kuning yang tampak di atas plat silika gel. Isolasi pada fraksi 6 tersebut diserap dengan serapan spektrofotometer namun tidak membentuk serapan maksimum sehingga jenis pigmen pada fraksi 6 ini tidak teridentifikasi. Sama halnya pada hasil isolasi pigmen pada fraksi 8 memiliki nilai $\operatorname{Rf} 0,25$ dan tampak pada plat silika gel dengan warna kuning. Pada fraksi 8 tidak teridentifikasi jenis pigmennya

$$
\text { Menurut Stahl (1985) ; }
$$

Harborne (1987), bahwa ada beberapa fraksi yang tidak teridentifikasi disebabkan oleh memudarnya warna fraksi tersebut sehingga tidak terbentuknya serapan maksimum dari spektrofotometer. Selanjutnya menurut Roth dan Blaschke (1998) bahwa memudarnya warna pada fraksi yang terbentuk di atas plat sebagai fase diam, dapat disebabkan oleh beberapa hal antara lain akibat pengaruh suhu, kelembaban udara, kejenuhan ruangan akan pelarut, konsentrasi dan komposisi pelarut serta faktor utama yaitu cahaya. Menurut Britton et al. (1995) dalam mengidentifikasi senyawa pigmen diperlukan mengisolasi kembali dengan sifat pengembang sesuai daerah polaritas.

Hasil isolasi pada fraksi 7 memiliki nilai $\mathrm{Rf} 0,34$ dan menampilkan warna kemerahan pada plat silika gel (Gambar 6). Hasil serapan maksimum spektrofotometer berada pada panjang gelombang $473 \mathrm{~nm}$. Menurut Britton et al. (1995) serapan spektrofotometer dari puncak tersebut teridentifikasi jenis pigmen astasen.

\section{KESIMPULAN}

Nilai konsentrasi pigmen total dari ekstrak kepiting $G$. albolineatus menunjukkan nilai tertinggi pada organ gonad dan darah. Sedangkan nilai kandungan pigmen total pada ekstrak organ kepiting $G$. albolineatus diperoleh nilai tertinggi berada pada organ gonad. Jenis-jenis pigmen yang teridentifikasi pada ekstrak organ karapas, lapisan epidermis, hepatopankreas, gonad dan darah dari kepiting $G$. albolineatus betina dengan larutan pengembang $P E$ dan Aseton yang bersifat semipolar yaitu: $\quad \beta$-karoten, ekinenon, kantaksantin, tipe adonirubin, astaksantin dan astasen.

\section{DAFTAR PUSTAKA}

Bliss, D.E., Mantel, L.H. 1982. Systematics, The Fossil Record and Biogeography in The Biologi of Crustacea. Volume 1, New York. America.

Britton, G., Jansen, S.L., Pfander, $\mathrm{H}$. 1995. Caratenoids. Volume 1B. Spectroscopy.

Basel, Switzerland.

Britton, G., Jansen, S.L., Pfander, H. 2004. Carotenoids handbook. Basel,. Switzerland. Birkhauser Veralg AG.

Britton, G., Jansen, S.L., Pfander, H. 2008. Carotenoids. Volume 4. Natural Functions. Basel, Switzerland.

Chang, R. 2010. Chemistry. Published The By McGraw-Hill Companies. New York.

Harborne, J.B. 1987. Metode Fitokimia: Penentuan Cara Medern Menganalisis Tumbuhan. ITB. Bandung 
Ismunandar. 2006. Pengantar Kimia. Penerbit Iwanami Kompany. Tokyo.

Landrum, J. T. 2010. Carotenoids Physical, Chemical, and Biological Fuction and Properties. CRC Press. New York.

Majchacheep, S. 1989. Marine Animal Of Thailand. Published By Prae Pittaya. Thailand

Matsjeh, S. 1999. Tlc. Thin Layer Chromatography. Fakultas Matematika dan IImu Pengetahuan Alam. Universitas Gadjah Mada. Yogyakarta.

Mantiri, D.H.M. 1997. These. Nature, Localization et Metabolisme des Cartenoides et des Complexes Caratenoproteiques au Cours de L'Evolution Embryonnaire et Larvaire du Hommard Europeen Homarus gammarus. Universite De Droit, D' Economie et des Sciences D' Aix Marseille.

Mantiri, D.H.M., Paransa, D.J., Koagouw, J.F.. 2002. Telaah Awal Kandungan Pigmen Larotenoid Pada Kepiting Biola Uca vocans jantan. Jurnal Perikanan dan IImu Kelautan. 1(1):43-47

Mantiri, D.H.M. 2004. The Carotenoproteins During Embryogenesis and Larva Developmen Of The European Lobster Homarus Gammarus. Genevieve Negre-Sadargues Jose-Carlos G. Milicua Rene Castiilo. Journal Of Crustacean Biology. 24(4):592-602.

Nontji, A. 1993. Laut Nusantara. Cetakan Kedua. Penerbit PT. Djambatan. Jakarta.

Paransa, D.J., Mantiri, D.H.M., Korompis F. 2002. Penentuan Kandungan Pigmen Karotenoid

$\begin{array}{lr}\text { Pada Kepiting } & \text { Grapsus } \\ \text { albolineatus (Lamarck) } & \text { Betina } \\ \text { Berdasarkan Beda Larutan } \\ \text { Pengembang } & \text { Pada } \\ \text { Kromatografi Lapis Tipis. Jurnal } \\ \text { Perikanan dan Ilmu Kelautan. } \\ \text { 1(3):42-46 }\end{array}$

Ruppert, E.E., Barnes, R.D. 1994. Invertebrata Zoology. Clemson University, Gettysburg Soutcorolini. Pennsylvania. College, 